\title{
Exports and governance: the role of private voluntary agrifood standards
}

Dela-Dem Doe Fiankor $^{\mathrm{a}^{*}}$, Inmaculada Martínez-Zarzoso ${ }^{\mathrm{b}, \mathrm{c}}$, Bernhard Brümmer $^{\mathrm{a}, \mathrm{d}}$

${ }^{a}$ University of Goettingen, Department of Agricultural Economics and Rural Development, Germany

${ }^{b}$ University of Goettingen, Department of Economics and Center for Statistics, Germany

${ }^{c}$ University Jaume I, Institute of International Economics, Castellón, Spain

${ }^{d}$ University of Goettingen, Centre for Biodiversity and Sustainable Land Use (CBL), Germany

*Corresponding author e-mail: dfianko@agr.uni-goettingen.de 


\section{Abstract}

The empirical evidence that institutional differences across countries affect bilateral trade is robust. The crucial question remains how countries can enhance trade amid these differences. In this paper, we measure the degree to which governance and institutions differ between countries as "governance distance". Using a sample of EU/EFTA imports, we examine how adopting private agrifood safety standards modify the effect of governance distance on exports of fruits and vegetables, in particular apples, bananas and grapes within a structural gravity framework. Our results show that while increasing governance distance hinders bilateral trade, the interaction of standards and the governance distance is positively associated with exports, hence partially offsetting the direct trade-inhibiting effects of the latter. GlobalGAP certified countries see the trade-inhibiting effects of governance distance on their exports reduced by about $50 \%$, ceteris paribus.

JEL classification: F14, L15, Q17, Q18

Keywords: Agricultural trade, GlobalGAP, Private food standards, Gravity model, Institutional quality 


\section{Introduction}

The question whether or not domestic institutions or institutional quality differences between countries affect bilateral trade flows has been examined extensively in the international trade (see, e.g., Anderson and Marcouiller, 2002; de Groot et al., 2004; Berden et al., 2014; MartínezZarzoso and Márquez-Ramos, 2018; Álvarez et al., 2018) and agricultural trade literature (see, e.g., Bojnec and Fertô, 2009; Olper and Raimondi, 2009; Huchet-Bourdon and Cheptea, 2011; de Mendonça et al., 2014). These studies provide robust evidence that answers this question generally in the affirmative. In effect, while international trade remains important to integrate developing countries into the global economy, missing or weak institutions will complicate international trade for their domestic firms (Goedhuys and Sleuwaegen, 2016).

An equally important question, but one which has received much less attention, is how countries overcome these institutional quality differences (Dimitrova et al., 2017). This is especially important for developing countries because they are dominated by small and medium-scale producers who need to work around this institutional void (Goedhuys and Sleuwaegen, 2016). This paper makes an empirical contribution to the literature by examining the role of private voluntary standards for fruits and vegetables as alternative governance mechanisms to bridge the bilateral institutional or governance distance. ${ }^{1}$ Thus, it is not another paper that shows that institutions matter for trade; but a discussion of one way to increase trade in the presence of institutional differences.

Voluntary standards and product certifications have proliferated, becoming almost a universal phenomenon (Busch, 2011; Swinnen, 2016). Producers, in both developed and developing countries, are embracing certifications as quality signalling mechanisms to access high-value markets. To what extent do these market access provisions hold for exporting countries with poor domestic institutions? Voluntary product certifications may have increased signalling effects among countries with extreme institutional quality differences or the

\footnotetext{
${ }^{1}$ We use the terms "institutional distance" and "governance distance" interchangeably in this paper.
} 
effectiveness of certification may be dampened under extreme institutional quality differences. ${ }^{2}$ This is an empirical question that to our knowledge has not been studied in the agricultural trade literature. In fact, relatively little attention has been devoted to the role of voluntary standards in the context of institutional gaps. ${ }^{3}$ This is nevertheless, essential. The increasing use of third-party audited standards to govern agrifood trade is an attempt by retailers to normalise agribusiness practices across countries (Ouma, 2010). The result, as we will argue, is that private standards counteract the trade-inhibiting effect of the institutional distance between countries.

We study this in the context of business-to-business relationships in the agrifood sector. Specifically, the case of producers targeting markets in the European Union (EU) and the European Free Trade Area (EFTA). This is important because the agrifood sector is particularly subject to quality standards, but constitutes a significant share of total exports in many developing countries. The EU/EFTA, a major export destination for many developing countries (Scoppola et al., 2018) and a market with strict food safety regulations (Kareem et al., 2018), provides a good setting for our study. We focus on GlobalGAP, which is possibly the most widely used agrifood standard globally. Retailers in many developed countries seek to protect their integrity and reputation by demonstrating "due diligence" from food safety scandals (Lockie et al., 2015). Retail-driven process standards in general, but GlobalGAP standards, in particular, provide them one such guarantee. GlobalGAP standards are subordinate to state legislation whenever the requirements of the state exceed those of the standard. Hence, they also act as de facto institutions enforcing food safety and quality whenever public regulations are weak or missing.

Our contributions to the literature are as follows. First, we combine the concept of “institutional distance” (Huchet-Bourdon and Cheptea, 2011; Dimitrova et al., 2017; Álvarez et al., 2018) with that of "standards as barriers or catalysts to trade" (Anders and Caswell, 2009; Swinnen, 2016) to develop a novel perspective of how voluntary standards create

\footnotetext{
${ }^{2}$ For example, corruption erodes trust in government efforts to regulate the conduct of firms, thereby increasing the signalling value of private certifications, however, widespread corruption can also extend distrust to private certification systems and reduce their credibility and signalling values (see, e.g., Montiel et al., 2012).

${ }^{3}$ One exception is Goedhuys and Sleuwaegen (2016).
} 
conditions that counter the trade-inhibiting effects of institutional distance. With growing research interest on the trade effects of voluntary standards, we should highlight that our findings are new. We are the first to consider their indirect trade effect from an institutional distance perspective. Second, using product level export data - at the six digits-level of the Harmonised System Classification — on apples (HS 080810 and HS 081330), bananas (HS 080300), and grapes (HS 080610 and HS 080620), we formally investigate institutional distance and trade at the product level. Related studies consider aggregate or sectoral trade flows; e.g., Álvarez et al. (2018) and Martínez-Zarzoso and Márquez-Ramos (2018) study how institutions affect total bilateral trade flows, while Huchet-Bourdon and Cheptea (2011) consider the agrifood sector by summing up data on all products listed under HS06. Hence, these studies do not exploit the product dimension of their datasets. Nonetheless, to test the generality of our findings to the broader high-value agrifood sector, we use aggregate GlobalGAP certified fruits and vegetable production in a country as a robustness check.

Empirically, we estimate a structural gravity model on a sample of EU/EFTA imports from 134 countries between 2010 and 2015. We augment the model with a composite index of time-varying country-pair differences in the six dimensions of the World Governance Indicators (WGI), which we call "governance distance", and its interaction with GlobalGAP standards to investigate the effect on trade flows. Our results confirm a trade impeding effect of governance distance on exports, mitigated by the interaction between governance distance and GlobalGAP, which has a trade-enhancing effect. Thus, conditional on certification the trade impeding effect of bilateral governance distance is reduced. These findings are robust to the product-specific analysis of apples, bananas, and grapes but also the aggregate fruits and vegetable sector, and to different measures of institutional quality. From a policy angle, voluntary certifications are viable means to improve exporting country reputations and increase trade even with differences in country-pair institutional quality.

The rest of the paper is structured as follows. Section 2 discusses conceptual issues related to institutional distance and private food standards. Section 3 deals with the empirical specification of the gravity model and related econometric issues. Section 4 describes the data 
and develops an index of time-varying bilateral institutional quality differences. Section 5 presents and discusses the estimation results and Section 6 concludes.

\section{Conceptual discussion and hypotheses}

We test two research questions in our empirical setting: (1) the extent to which bilateral governance distance affects trade flows and (2) the role of voluntary standards as a means to bridge these gaps. In this section, we conceptualise different pathways that may moderate the effects.

\subsection{Governance and exports}

International trade involves multiple countries that usually have different institutional environments, e.g., democracies tend to have better institutions regarding consumer and food safety regulations, and provisions for their legal enforcement (Yu, 2010). Thus, the relationship between firms in different countries is naturally subject to multiple difficulties. An exhaustive literature has established the trade cost implications of these institutional differences (e.g., Felbermayr and Toubal, 2010). Martínez-Zarzoso and Márquez-Ramos (2018) conceptualise these costs implications in three channels. First, good governance facilitates contracts and long-term agreements between firms in different countries. If institutional effectiveness is similar in both countries, traders can easily use and operate in each other's institutional environments. This reduces adjustment costs arising from natural unfamiliarity with international partners and lowers the insecurity related to transaction contingencies. The implication is that countries with similar ethical business environments will tend to trade more bilaterally (Horsewood and Voicu, 2012). As Li and Samsell (2009) argue, the time and cost of learning new rules and regulations are minimal for countries with similar domestic institutions. Second, good governance promotes investments and productivity improvements (see, e.g., Bojnec et al., 2014). Finally, good governance decreases uncertainty by increasing transparency, comparability and trust. This improves importers' trust in exporters (Yu, 2010) 
and reduces the transaction costs and costs associated with the risks of trading. The reverse is also true; for exporting countries with weak institutions, importers will have little or no trust in their products. This will increase trade costs and reduce their exports.

The empirical evidence is conclusive; poor institutional quality hinders exports by increasing trade costs. We review the empirical literature related to agrifood trade. ${ }^{4}$ Inferring from a micro-founded gravity equation, Olper and Raimondi (2009) is one of the earliest studies to highlight the trade cost effect of institutions in the food industry. This is followed by Huchet-Bourdon and Cheptea (2011) who show that for the 11 founding members of the European Monetary Union, trade in agricultural products is sensitive to the quality and similarity of institutions. Bojnec and Fertô (2012) investigate how EU enlargement and quality of governance improves the size and duration of their agrifood trade. To generate a measure of governance and institutions, they apply a principal component analysis to the WGIs. They find that good institutions improve food exports and duration in each of the EU market segments. Estimating a gravity model, Bojnec et al. (2014) show that the quality of institutions in both exporting and importing countries enhance bilateral agrifood trade for the BRIC countries. de Mendonça et al. (2014) show that issues such as property rights, quality of rural employment and adoption of national and international norms in agricultural activity are essential to enlarge trade flows between countries.

Premised on this discussion we hypothesise that increasing bilateral governance distance has a negative effect on agrifood trade ceteris paribus, i.e., the farther away countries are from each other in terms of their institutional quality, the less trade we will observe.

\subsection{Voluntary food standards as private governance institutions}

In many instances, retailers in developed countries ("the North") import their agricultural and food products from developing countries ("the South"). But, institutions and the ability to enforce strict food safety regulations in the North are better than in the South (Levchenko, 2007). Consider the case of the EU/EFTA; according to the EU Food Law (Regulation EC No

\footnotetext{
${ }^{4}$ We refer the interested reader to Martínez-Zarzoso and Márquez-Ramos (2018) who review the general trade literature that study governance as a first-order determinant of bilateral trade flow
} 
$178 / 2002$ ), where any food which is unsafe is part of a batch, it shall be presumed that all the food in that batch is also unsafe. It is the responsibility of retailers in the EU to ensure that banned substances are not applied or present on their imports from third countries. Retailers stand the risk of damaging their reputation and losing out financially if the quality of their imports is compromised.

Ensuring due diligence increases the transaction costs for retailers, especially where they cannot trust domestic institutions in the producing countries to ensure high standards. Exportoriented producers and firms operating in institutionally weak countries face difficulties in this regard, as buyers tend to infer the quality of their products partly from the generally poor reputation of their home countries' institutions (Montiel et al., 2012). As Hudson and Jones (2003) point out, because perceptions of quality have become associated with the level of development in the country of origin, developing countries find it especially difficult to signal quality to buyers. They are disproportionately hampered by information asymmetries and negative reputation effects (Goedhuys and Sleuwaegen, 2013) which necessitates signalling quality to their international partners through other means. For example, Dimitrova et al. (2017) find that when the differences in country-pair quality of institutions increase, uncertainty about exchanges heightens, and importers tend to rely more on an exporter's reputation for its people as a reassurance that exporting firms will be honest in their dealings. In other words, the more bilaterally distant the formal institutional environments between countries, the more beneficial the use of informal arrangements (Abdi and Aulakh, 2012).

Our point of departure is the argument that voluntary certification by exporters to a standard that is accepted in the importing country improves exporting country reputations by reducing the bilateral governance distance between the two countries. This effect is moderated through the transaction cost reducing effect of the standard for retailers in the importing country. When the quality of institutions differs widely between two countries, we argue that standards can act as surrogate governance institutions. They level the playing field by placing geographically dispersed firms on a common ground in terms of managerial practices, business language and conflict-settling procedures (Hudson and Jones, 2003; Goedhuys and Sleuwaegen, 2016). This 
will reduce the bilateral institutional distance across countries engaged in bilateral trade. In agricultural trade, importers can in many cases only judge the final product. In the presence of increasing bilateral governance distance, information asymmetries are pronounced and signalling quality becomes even more important. With bounded rationality, importers will look for proxies to assess product quality. Exporters that can provide quality assurance, e.g., via certification, gain a competitive edge (Cao and Prakash, 2011).

As traceability requirements (e.g., article 18.2 of the EU Food Law) ${ }^{5}$ get stricter, retailers are increasingly interested in the guarantee that not only the final products but also the production processes meet the required standards. The surge in the number of retailer-led standards, e.g., GlobalGAP, International Featured Standards, British Retail Consortium standards is, therefore, not surprising. The case of GlobalGAP standards is particularly interesting because it is fast becoming quasi-mandatory to assess high-value markets despite being legally voluntary. As a business-to-business standard, GlobalGAP certification resembles an attempt by retailers to enforce a system where individual farmers' skills are benchmarked against each other. This provides a mechanism for retailers to identify producers, regardless of country of origin, producing according to industry accepted standards, i.e., those who can signal quality through the possession of a certificate of conformity. This enhances the scopes of importers to gauge the quality performance of their suppliers and ensures the inclusion of distant suppliers (Ouma, 2010).

In the process, this reduces the transaction costs for retailers dealing with producers scattered across various countries, who may have different food safety standards and different abilities to enforce them. By outsourcing both the knowledge acquisition and the technical expertise required for design and ex-post monitoring of the standard, GlobalGAP allows both for a reduction in the costs of monitoring food safety standards at the farm level and ensuring that they comply with EU public regulations (Maze, 2017). However, it also induces extra costs for the producing party, which some have interpreted as the increasing power of retailers to pass

\footnotetext{
${ }^{5}$ The regulation states that "food and feed business operators shall be able to identify any person from whom they have been supplied with a food, a feed, a food-producing animal, or any substance intended to be, or expected to be, incorporated into a food or feed".
} 
on food safety risks through their supply chains (Lockie et al., 2013). For producers, GlobalGAP has "major" and "minor" musts that should be met along each stage of the production chain before certification is granted. ${ }^{6}$ But, the harmonisation of production processes across farms overrides to some extent the institutional quality differences between high-value importing countries and suppliers, especially from countries with weak domestic food safety regulations. Hence, producers who bear the costs and comply, nevertheless, may achieve a competitive advantage.

In summary, supply chain governance via GlobalGAP standards is an attempt to normalise spatially dispersed farming practices across countries (Ouma, 2010). Certification provides a shared frame of reference for both parties and increases importers' trust in products irrespective of the country of origin. By increasing the visibility of actions of actors on the supply-side (i.e., producers and suppliers) to actors on the demand-side (i.e., retailers and importers) of the value chain, standards enable the maintenance of trust in distant relationships (Lockie et al., 2015). Based on these arguments, we hypothesise that by reducing the transaction costs for retailers, private voluntary food certifications decrease the bilateral governance distance between countries.

\section{Empirical application}

To test our hypotheses, we estimate a structural gravity model of international trade. The gravity model describes one of the most stable relationships in economics: "interactions between large economic clusters are stronger than between smaller ones, and nearby clusters attract each other more than far-off ones" (van Bergeijk and Brakman, 2010, p.1). It has become the workhorse model for trade policy analysis. Our modelling approach is similar to Tadesse

\footnotetext{
6 "Major" control points for GlobalGAP include traceability (e.g., producers must guarantee that the product can be traced back to the farm by registering exact planting and harvesting dates), record keeping (e.g., producers are required to keep records on all substances applied to crops, exact amounts, and application dates), varieties and fertilisers (e.g., only certified/authorised seed varieties and fertilisers may be used; inorganic and organic fertilisers have to be stored separately from crops and seeds), irrigation (e.g., without contaminated water), Integrated Pest Management (e.g., pests must be dealt with in ecologically sensitive ways, crops must be treated with pesticides punctually if affected, and producers must ensure a minimum time between spraying and harvesting), harvesting and produce handling (e.g., hygienic treatment of harvested produce must be ensured).
} 
and White (2010) and Dimitrova et al. (2017) who assess the pro-export effect of immigrants on cultural distance, and the relationship between bilateral country reputation and export volume, respectively. Following Anderson and van Wincoop (2003), our augmented gravity model assumes a constant elasticity of substitution $(\sigma)$ and product differentiation by place of origin. In addition, prices differ among locations due to asymmetric bilateral trade costs. In its $\log -\log$ reduced form, the structural gravity model is specified as:

$$
\ln X_{i j k t}=\ln E_{j t}+\ln Y_{i k t}-\ln Y_{k t}+\left(1-\sigma_{k}\right) \ln \tau_{i j k t}-\left(1-\sigma_{k}\right) \ln P_{j k t}-\left(1-\sigma_{k}\right) \ln \Pi_{i k t}+\varepsilon_{i j k t}
$$

where $\mathrm{X}_{i j k t}$ is exports of product $k$ from exporting country $i$ to importing country $j$ in year $t . \mathrm{E}_{j t}$ is nominal GDP, which proxies the import demand of $j$ in $t . Y_{i k t}$ is the level of domestic production of $k$ in $i . Y_{k t}$ is aggregate world production and $P_{j k t}$ and $\Pi_{i k t}$ are the inward and outward multilateral resistance terms respectively. $\varepsilon_{i j k t}$ is the error term, which we cluster by product and country-pair at the same time. $\tau_{i j k t}$ are trade costs, which we define as the following multiplicative log-linear function:

$\ln \tau_{i j k t}=\gamma_{1} \ln$ Distance $_{i j}+\gamma_{2} \ln$ GovDist $_{i j t}+\gamma_{3}$ GlobalGAP $_{i k t}+\gamma_{4}$ GovDist $_{i j t} \times$ GlobalGAP $_{i k t}+$ $n=79 \gamma n \Theta i j$

As we highlight in the conceptual discussion, institutional quality differences between countries affect trade costs. Simultaneously, compliance with retailer-led standards like GlobalGAP are costs of doing business - that may, or may not, enhance profitability through improved market access (Lockie et al., 2015) — especially for producers targeting high-value export markets. Thus, we argue that the effects of both institutional quality differences and GlobalGAP certification on trade is via the trade cost channel. We augment the trade cost component of our model with GovDist ${ }_{i j t}$ which proxies institutional quality differences between country pairs and a dummy variable, GlobalGAP $i k t$, which is our measure of the certification status of the exporting country. GovDist $i j t$. GlobalGAP $i k t$ is the interaction of the two variables. Distance $_{i j}$ is the bilateral distance between country-pairs, RTA ijt $_{i}$ is a dummy that denotes 
membership in a regional trade agreement, and Tariff $f_{i j k t}$ is product-specific ad valorem tariff. $\theta_{i j}$ is a vector of time-invariant traditional gravity covariates including dummies for sharing a common language, colonial ties, and a common border.

For estimation purposes, we introduce the trade cost component, $\tau_{i j k t}$ into equation (1) and specify a standard augmented gravity model in its log-linear form as:

$\ln X_{i j k t}=\alpha_{t}+\psi_{i}+\rho_{j}+\phi_{k}+\beta_{0}+\beta_{1} \ln$ Production $_{i k t}+\beta_{2} \ln \mathrm{GDP}_{j t}+\beta_{3} \ln$ Distance $_{i j}+\beta_{4}$ GovDist $_{i j t-1}+\beta_{5}$ GlobalGAP $_{i k t-1}+\beta_{6}$ GovDist $_{i j t-1} \times$ GlobalGAP $_{i k t-1}+\beta_{7}$ RTA $_{i j t}+\beta_{8} \ln (1+$ $n=911 \gamma n \Theta i j+\varepsilon_{i j k t}$

where $\alpha_{t}, \psi_{i}, \rho_{j}$, and $\phi_{k}$ are year, exporter, importer, and product fixed effects, respectively. Production $_{i k t}$ is the domestic production of product $k$ in the exporting country and GDP Git $_{t}$ is the Gross Domestic Product of the importing country. These variables measure the supply-side capacity of the exporting country and the demand-side capacity of the importing countries, respectively. All other variables remain as defined in equation (2). To deal with the potential endogeneity of institutions and certifications due to reverse causality, we use a one-year lag of both variables (see, e.g., Dimitrova et al., 2017; Álvarez et al., 2018).

The model as specified in equation (3) is at best atheoretical because it does not account fully for the theoretical multilateral resistance terms $\mathrm{P}_{j k t}$ and $\prod_{i k t}$ in equation (1) (Anderson and van Wincoop, 2003) - which in our sectoral panel data setting should be time and product varying (Baldwin and Taglioni, 2007). What this means is that the country fixed effects in equation (3) must vary with product and time. To that effect, our theoretically specified ordinary least squares (OLS) model is:

$\ln X_{i j k t}=\psi_{i k t}+\lambda_{j k t}+\beta_{0}+\beta_{1}$ ln Distance $_{i j}+\beta_{2}$ Language $_{i j}+\beta_{3}$ Colony $_{i j}+\beta_{4}$ Contiguity $_{i j}+\beta_{5}$ GovDist $_{i j t-1}+\beta_{6}$ GovDist $_{i j t-1} \times$ GlobalGAP $_{i k t-1}+\beta_{7}$ RTA $_{i j t}+\beta_{8} \ln \left(1+\operatorname{Tariff}_{i j k t}\right)+\varepsilon_{i j k t}$

where $\psi_{i k t}$ and $\lambda_{j k t}$ are the exporter-product-time and importer-product-time fixed effects respectively. Apart from being consistent with the gravity theory, the inclusion of these terms account for the size terms (i.e., $\mathrm{GDP}_{j t}$ and Production $_{i k t}$ ) and the certification measure $\left(\right.$ GlobalGAP $\left._{i k t}\right){ }^{7}$ They also account for unobservable variables that have the country-product-

\footnotetext{
${ }^{7} \mathrm{We}$ do not include the main effect for GlobalGAP ${ }_{i k t}$ in equations (4) and (5) because they are accounted for by the exporter-product-time effects.
} 
time dimension (e.g., non-tariff measures, infrastructure, domestic institutions), thus mitigating any further omitted variable biases that may lead to endogeneity in our model specification. Furthermore, the specification in equations (3) and (4) requires log transforming the dependent variable. This may result in significant loss of information in micro-settings like agrifood trade where zero valued trade flows are ubiquitous. Since we estimate our gravity model at the very disaggregated HS6 digit level, the issue of zeroes is even more pronounced-i.e., $81 \%$ of our observed trade flows are zero. As an alternative to the OLS specification, we adopt the Poisson pseudo-maximum-likelihood (PPML) estimator à la Santos Silva and Tenreyro (2006, 2011) in equation (5). The estimator's log-linear objective function allows us to specify the gravity equation in its multiplicative form without log-transforming the dependent variable, and is consistent under heteroskedasticity.

$X_{i j k t}=\exp \left[\psi_{i k t}+\lambda_{j k t}+\beta_{0}+\beta_{1} \ln\right.$ Distance $_{i j}+\beta_{2}$ Language $_{i j}+\beta_{3}$ Colony $_{i j}+\beta_{4}$ Contiguity $_{i j}+$

$\beta_{5}$ GovDist $_{i j t-1}+\beta_{6}$ GovDist $_{i j t-1} \times$ GlobalGAP $_{i k t-1}+\beta_{7}$ RTA $\left._{i j t}+\beta_{8} \ln \left(1+\operatorname{Tariff}_{i j k t}\right)\right]+\varepsilon_{i j k t}$

Similar variable definitions hold as in equation (2). Our hypotheses are confirmed when the coefficient on the governance distance measure is negative (i.e., $\beta_{5}<0$ ), but we expect a positive coefficient on the interaction term (i.e., $\beta_{6}>0$ ).

\section{Data}

Growing interest in studying the quality of governance institutions has given rise to quantitative governance indicators from different sources. These include data from the International Country Risk Guide rating systems, Freedom House, Transparency International's Corruption Perception Index, and the World Bank's WGIs (Arndt and Oman, 2006). But, the WGIs are the most comprehensive institutional indicators currently available for many countries (Arndt and Oman, 2006; Lio and Liu, 2008; Huchet-Bourdon and Cheptea, 2011; Berden et al., 2014; Álvarez et al., 2018). Hence, we calculate our governance distance measure using data on the WGIs. The WGIs are composed of six indicators (Table 1$)^{8}$ that are based on several hundreds of variables obtained from 31 underlying data sources reporting the perceptions of governance of a large number of survey respondents, and expert assessments of

\footnotetext{
${ }^{8}$ These variables are more or less standard in the literature and are not discussed in details here. We refer the interested reader to de Groot et al. (2004), Arndt and Oman (2006), and Berden et al. (2014).
} 
non-governmental organisations, commercial business information providers, and public sector organisations worldwide (Kaufmann et al., 2011).

Each of these indicators, measured in units ranging from -2.5 (worst) to 2.5 (best), represents a different dimension of governance in a country which can potentially affect trade. Since our interest is in how these measures vary across country-pairs, we transform the country-varying WGIs into country-pair varying variables using an index defined in equation (6). There is an added advantage to this approach; it respects the structural properties of the gravity model by allowing estimates with the proper set of country-time fixed effects. Recent work that has followed this approach include Martínez-Zarzoso and Márquez-Ramos (2018) and Álvarez et al. (2018). Their approaches yield indices that vary bilaterally over time across each of the individual WGIs. We, on the other hand, are interested in a composite measure of bilateral and time-varying institutional quality. Following Kogut and Singh (1988), Abdi and Aulakh (2012), and Dimitrova et al. (2017), and introducing the time dimension $t$ of our dataset, we calculate the bilateral governance distance between country pairs as the standardised difference between the importing and exporting country scores on each of the six WGIs:

GovDist $_{i j t}=\sum_{n=1}^{6}\left(W G I_{j n t}-W G I_{i n t}\right)^{2} / 6 V_{n t}$

where GovDist ${ }_{i j t}$ is the bilateral governance distance between exporter $i$ and importer $j$ in year $t, \mathrm{WGI}_{j n t}$ and $\mathrm{WGI}_{i n t}$ are the annual values for the $\mathrm{n}^{\text {th }}$ WGI indicator for $i$ and $j$, respectively, and $\mathrm{V}_{n t}$ is the variance of the $\mathrm{n}^{\text {th }}$ WGI across all countries in the dataset. The indicator is minimised at zero for countries with similar institutional qualities and maximised for countries that are institutionally furthest apart. In our sample, the average ranges from 0.014 (i.e., the Netherlands - Canada) to 17.69 (i.e., Finland - Somalia). Using the case of Germany as an importing country, Figure (1) shows the average bilateral governance distance over the period 2010 to 2015. The darker regions, i.e., countries in Africa and the Middle East, imply large institutional quality differences with Germany. Countries with the lowest governance gaps include other countries in the EU, EFTA, the United States, Canada, Chile, Japan and Australia. 
To test the second hypothesis, we use GlobalGAP certifications as our preferred private voluntary standard. We premise this on the observation that GlobalGAP has become the most widely applied retailer-led quality assurance scheme for agrifood production since its inception in $1997 .{ }^{9}$ As we show in Table 2 , the number of producers seeking certification has increased over time. The choice of GlobalGAP also makes the EU and EFTA ideal export destinations because GlobalGAP is considered a minimum requirement to access their agrifood markets. In 2007, in an attempt to mark their global relevance, they effected a name change from EUREPGAP to GlobalGAP. Hence, while GlobalGAP still wields a growing global influence, we expect their effects to be stronger for exports targeting the EU and EFTA. The dataset was provided by the GlobalGAP Secretariat in Cologne, Germany.

GlobalGAP certifies both crops, livestock, and aquaculture. We limit our study to the fruit and vegetable crops sector, specifically, apples, bananas and grapes, given their relative importance among certified products. Together with potatoes, these products are the most GlobalGAP certified open field crops by area (GLOBALGAP, 2012), representing more than $30 \%$ of all GlobalGAP certified fruits and vegetable production (Table 2). Moreover, to test the generality of our findings to the broader high-value agrifood sector, we use aggregate GlobalGAP certified fruits and vegetable production in a country as a robustness check. Unlike the productspecific data on apples, bananas, and grapes, this dataset does not allow us to identify the specific crops certified within a country. It aggregates data on all products that can be certified within the GlobalGAP sub-scope 'Fruits and Vegetables'.

Our dataset covers exports from 134 non-EU/EFTA countries to 31 EU/EFTA countries over the period 2010 to 2015 . We omit re-exports from non-producing countries. To match the available product-specific GlobalGAP data, our set of exporters is limited to apple, banana and grape producing countries (see Table A1 of the online appendix). Over the study period, 25 exporting countries had at least one certified apple producer, 36 exporting countries had at

\footnotetext{
${ }^{9}$ In international agri-food trade, private standards are, ubiquitous nevertheless, GlobalGAP standards are more widespread, e.g. Mohammed and Zheng (2017) show that for the 131 countries they study, the number of GlobalGAP certified sites is normally several times larger than that certified to other private standards (i.e. BRC, FSSC 22000, ISO 22000, PrimusGFS, SQF).
} 
least one certified banana producer and 30 exporting countries had at least one certified grape producer. Hence, for each of these countries, the GlobalGAP ${ }_{i k t}$ dummy takes the value of 1.

The remaining gravity model data come from different sources. The bilateral trade data on fresh and dried apples (HS 080810 and 081330), fresh and dried bananas (HS 080300) ${ }^{10}$ and, fresh and dried grapes (HS 080610 and 080620) comes from the United Nations Comtrade database and is downloaded at the six-digit HS2007 level. ${ }^{11}$ Data on distance, colonial ties, common language, and contiguity are from the Centre d'Etudes Prospectives et d'Informations Internationales. Data on effectively applied tariffs are from the International Trade Centre, and data on regional trade agreements are from De Sousa (2012). Detailed summary statistics on all included variables are presented in the online appendix (Table A2).

\section{Results and discussion}

\subsection{Main results}

To allow for comparison across model specifications and to conclude whether our variables of interest can be estimated reliably regardless of the estimation procedure, we present and discuss the results of both the OLS and PPML models. ${ }^{12}$

Table 3 reports the estimated coefficients in equations (4) and (5). In many cases, consistent with the literature the estimates of the PPML model are smaller than in the OLS specification (Santos Silva and Tenreyro, 2006). The signs and magnitudes of the traditional gravity control variables are all consistent with the gravity literature. Bilateral distance and tariffs decrease trade, but linguistic similarity, and countries that share a common border, past colonial ties or are members of a trade agreement are more likely to trade than otherwise. The coefficient estimates on the Tariff and RTA variables are not always statistically significant across our model specifications. This is not surprising because the sample of importing countries contains EU and EFTA countries and therefore there is little variation in the RTA and tariff variables.

\footnotetext{
${ }^{10}$ Banana trade flows recorded in the six-digit HS2007 classification includes plantains. But trade volumes are low compared to bananas, and should not alter our results.

${ }^{11}$ We limit the bilateral trade data to six years to match the available product-specific GlobalGAP data

12 To deal with the high-dimensional fixed effects in our model specifications, we use the user-written commands reghdfe (Correia, 2016) and poi2hdfe (Guimaraes and Portugal, 2010) in Stata.
} 
In support of our first hypothesis, the coefficient estimate on our governance dissimilarity measure, GovDist $t_{i j t-1}$, is negative and statistically significant at any conventional level in both model specifications. Thus, with increasing bilateral governance distance, bilateral trade decreases. This implies that for retailers in the EU and EFTA, when deciding where to source their agrifood products, they prefer countries with institutional qualities similar to those existing in the EU and EFTA.

Next, we test the effect on the interaction of governance distance and GlobalGAP standards. We enter the interaction term GovDist $i_{i j-1} \times$ GlobalGAP $_{i k t-1}$, and the constitutive terms of the interaction into the models in columns (2) and (4). The GlobalGAP ${ }_{i k t-1}$ term is omitted from the tables as they are accounted for by the exporter-product-time fixed effects. In support of our hypothesis, the coefficient estimate on the interaction term is positive and statistically significant. Hence, the more distant the governance gap between country pairs, the more effective the use of certification.

Based on these findings, we assess the differential effect of bilateral governance distance on trade flows depending on the GlobalGAP certification status of the exporting country. From equations (4) and (5), the effect for certified countries includes the direct effect of the governance gap proxy and the coefficient on the interaction term (i.e., $\widehat{\beta_{2}}+\widehat{\beta_{3}} *$ GlobalGAP $\left._{i k t-1}\right)$. Thus, empirically based on our a priori expectation, a negative governance gap effect becomes less negative if the interaction term is positive. Specifically, for noncertified countries, the effects on trade are the direct GovDist ${ }_{i j t-1}$ effects (i.e., - 0.599 in column 2 and -0.450 in column 4). For certified countries, the trade-inhibiting effect of governance distance is about half the magnitude for non-certified countries (i.e., -0.296 in column 2 and 0.185 in column 4$)$.

Our results imply that even though bilateral governance distance has a trade impeding effect on trade flows, the negative effects are smaller for certified compared to non-certified countries. This suggests that product certification, which signals product quality, is important in enhancing exports even for country pairs with big differences in institutional quality. This is because where public food safety regulations are missing or, when available, institutions to enforce them are weak, the GlobalGAP standard provides the retailer with an instrument to 
manage their risks (Lockie et al., 2013). However, because the coefficient on the interaction term is smaller in magnitude than the direct effect of GovDist ${ }_{i j t-1}$ (i.e., $\left|\beta_{6}\right|<\left|\beta_{5}\right|$ ), the GlobalGAP certification effect is not sufficiently large to completely eliminate the negative effects of governance distance.

To put the findings in perspective, we use the results of the PPML specification. For the average effect in column (3), all else remaining equal, a one standard deviation increase in the bilateral governance gap index $(=2.740)$, decreases trade flows by about $60 \%{ }^{13}$ This effect approximately corresponds to a change in GovDist $t_{i j t}$ from Austria - USA $(=0.12)$ to that of Austria - Turkey (=2.86), Germany - Australia (=0.03) to that of Germany - Albania (=3.09), or from Sweden - Ghana $(=3.33)$ to that of Sweden - Guatemala $(=6.18)$. Thus, if the institutional distance between Austria - Turkey, Germany - Albania, and Sweden - Ghana decreases by one standard deviation, apple exports from Turkey to Austria, grape exports from Albania to Germany and banana exports from Guatemala to Sweden will increase by $60 \%$. For the conditional effects in column (4), the trade reducing effect of a one standard deviation increase in the governance distance measure is $124 \%$ for non-certified countries but decreases to about $51 \%$ for certified producing countries.

To gain further insights into the analysis, we disaggregate the composite governance distance index into its individual components and assess how each of them influences trade and interacts with GlobalGAP standards. In the spirit of Álvarez et al. (2018) we enter the six different components; Voice and Accountability $\left(\mathrm{VA}_{i j t}\right)$, Political Stability $\left(\mathrm{PS}_{i j t}\right)$, Rule of Law $\left(\mathrm{RL}_{i j t}\right)$, Control of Corruption $\left(\mathrm{CC}_{i j t}\right)$, Government Effectiveness $\left(\mathrm{GE}_{i j t}\right)$, and Regulatory Quality $\left(\mathrm{RQ}_{i j t}\right)$ individually into the model specifications. For brevity, the results of the analysis presented in the online appendix (Table A3) show only variables related to the governance measures. ${ }^{14}$ The results naturally vary by indicator, but the main finding of a negative effect of institutional distance on trade and a positive interaction effect with GlobalGAP standards is robust for each indicator; confirming our main findings. ${ }^{15}$

\footnotetext{
${ }^{13} 2.740 \times 0.217=0.595$.

${ }^{14}$ The full table of results are available upon request from the authors.

${ }^{15}$ This also shows that we do not lose valuable information by aggregating the separate measures into a onedimensional indicator. Moreover, the coefficients of $\mathrm{RL}_{i j t-1} \times \mathrm{GlobalGAP}_{i k t-1}$ and $\mathrm{RQ}_{i j t-1} \times \mathrm{GlobalGAP}_{i k t-1} \operatorname{are}$ not statistically significant in the PPML model. Regulatory quality $\left(\mathrm{RQ}_{i j t}\right)$ and rule of law $\left(\mathrm{RL}_{i j t}\right)$ are related to the implementation of regulations and policies and their enforcement. These aspects of governance may be less
} 
We also explore the heterogeneity of the effect across products and the development level of the certified exporting country. We define two levels of development based on the World Bank's income classification: “developing” (all countries listed as middle and low income) and "developed" (all countries listed as high income). The results of the analysis presented in columns (1) and (2) of Table 4 show that our findings are driven by developing country exports. The statistically non-significant findings for developed countries are in line with recent empirical findings that the GlobalGAP certification-trade effect is larger for developing countries compared to developed countries (Fiankor et al., 2017; Andersson, 2018). By products, the positive effect of GlobalGAP certification on the bilateral governance distance is economically substantial for grapes and apples, but remain small for bananas. The results for banana, reflect in part the special nature of the banana export market, especially in the EU, where they are considered sensitive products and have often been regulated by specific import regimes. Given the low level of banana production in the EU/EFTA, and the reputation especially of the EU as the number one banana consumption market globally, it appears that other bilateral trade policies aside certification are shaping the banana import market, e.g., the EU's preferential trade agreements and long-standing banana relations with the African Caribbean and Pacific countries, and recent bilateral trade agreements with banana-producing Latin American countries. The historic presence of well-established banana plantations (e.g., Dole, Chiquita, Fyffes, Del Monte, Compagnie Fruitière) that have always structured the supply to the world market (UNCTAD, 2016) may also explain the findings for banana. These vertically integrated firms often have their own production units in producer countries, and develop quality standards internal to the firm. Competing voluntary certification schemes for banana are also becoming popular. While GlobalGAP still certifies the largest banana area globally, Fairtrade, Organic and Rainforest Alliance/SAN certified banana area increased by almost $60 \%, 18 \%$ and, 28\%, respectively since 2008 (Lernoud et al., 2015). Given the

relevant for exporting firms trying to signal quality via certification than issues concerning the quality of public services (part of Government Effectiveness), or some forms of corruption; all of which are closely related to "behind the border" trade barriers affecting trade flows. 
importance of banana in the EU, bananas certified to other standards may be just as important as GlobalGAP.

\subsection{Robustness checks}

In this section, we conduct a series of robustness checks to confirm the reliability of our findings. For comparative purposes, we extend the analysis to include all producing countries as exporters and all importing destinations (Table 5). This sample includes bilateral trade flows between 163 producing countries and 157 importing countries (see Table A2 of the online appendix). All estimated coefficients remain consistent with the gravity theory. In the OLS case, the coefficients on colonial ties and common language become statistically significant compared to the estimates in Table 3. Moreover, membership of a trade agreement increases trade by about $70 \%{ }^{16}$, while a $10 \%$ increase in bilateral tariffs decreases trade by $42 \%$ in column (1). Focusing on our variables of interest, the trade inhibiting effect of bilateral governance distance and the pro-export effect of the interaction term remains robust. The magnitudes are nevertheless smaller than in our main specification and the coefficient on the interaction term is statistically insignificant in the PPML specification in column (4). This latter finding is due to the significant heterogeneity in the sample of importers and the fact that for some developing country importers certification may not be that important as for importers in developed countries. ${ }^{17}$

As further checks of the generality of our findings, we extend our analysis to all GlobalGAP certified fruits and vegetables. Hence this part of the analysis re-estimates our baseline specification, but considers an aggregate of products listed under HS07 (i.e., edible vegetables, and certain roots and tubers), HS08 (i.e., edible fruits and nuts) and the spices listed in HS09. ${ }^{18}$ To ensure theoretical consistency, we control for the multilateral resistance terms using

\footnotetext{
${ }^{16}$ Dummy variables are interpreted as $[\exp (\beta)-1] \times 100 \%$.

${ }^{17}$ To test this empirically, we estimate equations (4) and (5) splitting the sample between two importer groups: EU/EFTA and non-EU/EFTA. The interaction term remains statistically insignificant and economically small in magnitude for non-EU/EFTA importers. The results are available upon request from the authors.

${ }^{18}$ In this dataset, it is not possible to identify the number of product $k$ specific producers in country $i$. It aggregates data on all products that can be certified within the GlobalGAP sub-scope 'Fruits and Vegetables'.
} 
importer-time and exporter-time fixed effects. The findings reported in Table 6 confirm our main findings. Hence, our product-level findings in Table 3 can be extended to the broader agrifood sector.

As another exercise, we re-estimate the product-level specifications, but use instead of a GlobalGAP certification dummy, the number of certified producers in each exporting country. The results presented in the online appendix (Table A5) are consistent with our previous findings and confirm our main hypotheses. However, the coefficient on the interaction term is statistically significant in the OLS but not the PPML model. A possible reason for this finding is that retailers in the importing countries care mainly about the certification status of the exporting countries rather than how widespread the standard is within the country.

Finally, to see how sensitive our findings are to the choice of institutional quality measure, we use data from two other sources: (1) the Legatum Prosperity Index (Lind, 2014) — subindices include legal and political environment, physical property rights and intellectual property rights - and (2) the Economic Freedom of the World index (Murphy and Lawson, 2018) - sub-indices include size of government, legal system and property rights, sound money, freedom to trade internationally and regulations. The results represented in the online appendix (Table A6) show that our hypotheses are confirmed regardless of the measure of institution we use.

\section{Conclusion}

Much of the existing literature has shown that governance and institutions are important drivers of trade and economic growth. Similarities in governance and institutional quality measures across countries enhance bilateral trade flows. Hence, retailers in countries with good institutions will choose to source their products from countries with similar or better domestic institutions. Aside from the reputational damage associated with potential food scares, institutional dissimilarities also impose significant costs for trade. Hence, the more dissimilar country-pairs the less trade will be observed. Much less attention has, however, been paid to how exporting countries in low-quality institutional regimes can overcome these differences. 
This paper evaluates first, the effect of bilateral differences in governance and related institutions across countries on agrifood trade. Retailers, especially in high-value markets such as the EU and EFTA, are increasingly becoming concerned about traceability, quality of production processes and final products. Thus, second, we argue that private food standards and certifications act as surrogate institutions that help to overcome these differences at the country level. We are not aware of any existing studies that test this hypothesis empirically in the agricultural trade literature.

Empirically, our gravity model estimates confirm the trade reducing effect of bilateral governance distance on trade flows. But in addition, we also find that the trade impeding effects vary depending on whether the exporting country is certified to GlobalGAP standards or not. For certified exporting countries, the trade impeding effects are much lower compared to their non-certified counterparts, especially for exports to the EU and EFTA. Hence, we show that certification exerts a pro-export effect that partially offsets the trade-inhibiting effects of bilateral governance distance at the country level. Our findings are robust to the productspecific analysis of apples, bananas, and grapes but also the aggregate fruits and vegetable sector, and to different measures of institutional quality.

These findings have important policy implications. For producers and firms targeting highvalue markets but are located in countries with low quality of existing domestic public institutions, getting certified to a standard that is accepted in the importing country can help overcome the negative reputation effects associated with their geographical locations. Undoubtedly, certification in itself is not enough to overcome the total bilateral governance distance at the country level. Nevertheless, it is a viable alternative to reduce trade costs and enhance trade. We leave for further research the evaluation of the effect of private standards on exports from developing to developed countries using firm-level data. 
Acknowledgments: This research was financially supported by the German Research Foundation (DFG) through the GlobalFood Program (RTG 1666) and the SFB 990 (project number 192626868). We thank the GlobalGAP Head Office for providing us with data on certification. We appreciate comments from the editor, two anonymous referees, Stephan von Cramon-Taubadel, Hengrong Luo and participants of the 20th Göttingen workshop on International Economic Relations and the $30^{\text {th }}$ International Conference of Agricultural Economists in Vancouver. Dela-Dem Doe Fiankor gratefully acknowledges financial support from the Katholischer Akademischer Ausländer-Dienst. Inmaculada Martínez-Zarzoso gratefully acknowledges financial support from the Spanish Ministry of Economy and Competitiveness, Project ECO2017-83255-C3-3-P (AEI, FEDER, EU) and from project UJIB2017-33.

\section{References}

Abdi, M., Aulakh, P. S., 2012. Do country-level institutional frameworks and interfirm governance arrangements substitute or complement in international business relationships? J. Int. Bus. Stud. 43(5), 477-497.

Álvarez, I. C., Barbero, J., Rodríguez-Pose, A., Zofío, J. L., 2018. Does institutional quality matter for trade? Institutional conditions in a sectoral trade framework. World Dev. 103, $72-$ 87.

Anders, S. M., Caswell, J. A., 2009. Standards as barriers versus standards as catalysts: assessing the impact of HACCP implementation on US seafood imports. Am. J. Agric. Econ. 91(2), 310-321.

Anderson, J. E., Marcouiller, D., 2002. Insecurity and the pattern of trade: An empirical investigation. Rev. Econ. Stat. 84(2), 342-352. 
Anderson, J. E., van Wincoop, E., 2003. Gravity with gravitas: a solution to the border puzzle. Amer. Econ. Rev. 93(1), 170 - 192.

Andersson, A., 2018. The trade effect of private standards. Europ. Rev. Ag. Econ. jby027 Arndt, C., Oman, C., 2006. Uses and abuses of governance indicators. Development Centre Studies, Organization for Economic Development and Co-operation.

Baldwin, R., Taglioni, D., 2007. Trade effects of the Euro: a comparison of estimators. J. Econ. Integration 22(4), 780-818.

Berden, K., Bergstrand, J. H., Etten, E., 2014. Governance and globalisation. World Econ. $37(3), 353-386$.

Bojnec, Š., Fertô, I., 2009. The institutional determinants of bilateral agricultural and food trade. APSTRACT 4(3-4), 53-57.

Bojnec, Š., Fertô, I., 2012. Does EU enlargement increase agro-food export duration? World Econ. 35(5), 609-631.

Bojnec, Š., Fertô, I., Fogarasi, J., 2014. Quality of institutions and the BRIC countries agrofood exports. China Agr. Econ. Rev. 6(3), 379-394.

Busch, L., 2011. Standards: Recipes for reality. MIT Press, Cambridge, MA.

Cao, X., Prakash, A., 2011. Growing exports by signaling product quality: trade competition and the cross-national diffusion of ISO 9000 quality standards. J. Pol. Anal. Manage. 30(1), $111-135$.

Correia, S., 2016. REGHDFE: Stata module to perform linear or instrumental-variable regression absorbing any number of high-dimensional fixed effects. Statistical Software Components, Boston College Department of Economics.

de Groot, H. L., Linders, G.-J., Rietveld, P., Subramanian, U., 2004. The institutional determinants of bilateral trade patterns. Kyklos 57(1), 103-123. 
de Mendonça, T. G., Lirio, V. S., Braga, M. J., da Silva, O. M., 2014. Institutions and bilateral agricultural trade. Procedia Econ. Financ. 14, 164-172.

De Sousa, J., 2012. The currency union effect on trade is decreasing over time. Econ. Lett. 117(3), 917-920.

Dimitrova, B. V., Korschun, D., Yotov, Y. V., 2017. When and how country reputation stimulates export volume. Int. Mark. Rev. 34(3), 377-402.

Felbermayr, G. J., Toubal, F., 2010. Cultural proximity and trade. Europ. Econ. Rev. 54(2), 279-293.

Fiankor, D.-D. D., Flachsbarth, I., Masood, A., Brümmer, B., 2017. Does GlobalGAP certification promote agrifood exports? GlobalFood Discussion Papers 112, RTG 1666 GlobalFood. Georg-August-University of Goettingen.

GLOBALGAP, 2012. GLOBALGAP Annual Report 2012. Technical report, GLOBALG.A.P. c/o FoodPLUS GmbH.

Goedhuys, M., Sleuwaegen, L., 2013. The impact of international standards certification on the performance of firms in less developed countries. World Dev. 47, 87-101.

Goedhuys, M., Sleuwaegen, L., 2016. International standards certification, institutional voids and exports from developing country firms. Int. Bus. Rev. 25(6), 1344-1355.

Guimaraes, P., Portugal, P., 2010. A simple feasible procedure to fit models with highdimensional fixed effects. Stata Journal 10(4), 628.

Horsewood, N., Voicu, A. M., 2012. Does corruption hinder trade for the new EU members? Economics-Kiel 6(47), 1-28.

Huchet-Bourdon, M., Cheptea, A., 2011. Informal barriers and agricultural trade: does monetary integration matter? Agr. Econ. 42(4), 519-530.

Hudson, J., Jones, P., 2003. International trade in 'quality goods': signalling problems for developing countries. J. Int. Dev. 15(8), 999-1013. 
Kareem, F. O., Martínez-Zarzoso, I., Brümmer, B., 2018. Protecting health or protecting imports? Evidence from EU non-tariff measures. Int. Rev. Econ. Finance 53, 185-202.

Kaufmann, D., Kraay, A., Mastruzzi, M., 2011. The worldwide governance indicators: methodology and analytical issues. Hague J. Rule Law 3(2), 220-246.

Kogut, B., Singh, H., 1988. The effect of national culture on the choice of entry mode. J. Int. Bus. Stud. 19(3), 411-432.

Lernoud, J., Potts, J., Sampson, G., Voora, V., Willer, H., Wozniak, J., 2015. The State of Sustainable Markets-Statistics and Emerging Trends 2015. ITC, Geneva.

Levchenko, A. A., 2007. Institutional quality and international trade. Rev. Econ. Stud. 74(3), 791-819.

Li, S., Samsell, D. P., 2009. Why some countries trade more than others: the effect of the governance environment on trade flows. Corp. Gov. 17(1), 47-61.

Lind, N., 2014. Legatum prosperity index. In: Michalos, A. C. (Ed.), Encyclopedia of Quality of Life and Well-Being Research, pp. 3529-3530, Springer Netherlands.

Lio, M., Liu, M.-C., 2008. Governance and agricultural productivity: a cross-national analysis. Food Pol. 33(6), 504-512.

Lockie, S., McNaughton, A., Thompson, L.-J., Tennent, R., 2013. Private food standards as responsive regulation: the role of national legislation in the implementation and evolution of GLOBALG.A.P. Int. Jrnl. of Soc. of Agr. \& Food 20(2).

Lockie, S., Travero, J., Tennent, R., 2015. Private food standards, regulatory gaps and plantation agriculture: social and environmental (ir)responsibility in the Philippine export banana industry. J. Clean. Prod. 107, 122-129.

Martínez-Zarzoso, I., Márquez-Ramos, L., 2018. Exports and governance: is the Middle East and North Africa region different? World Econ. 42(1), 143-174.

Maze, A., 2017. Standard-setting activities and new institutional economics. J. Inst. Econ. 
13(3), 599-621.

Mohammed, R., Zheng, Y., 2017. International diffusion of food safety standards: The role of domestic certifiers and international trade. J. Agr. Appl. Econ. 49(2), 296-322.

Montiel, I., Husted, B. W., Christmann, P., 2012. Using private management standard certification to reduce information asymmetries in corrupt environments. Strateg. Manage. J. 33(9), 1103-1113.

Murphy, R. H., Lawson, R. A., 2018. Extending the economic freedom of the world index to the cold war era. Cato J. 38, 265.

Olper, A., Raimondi, V., 2009. Patterns and determinants of international trade costs in the food industry. J. Agric. Econ. 60(2), 273-297.

Ouma, S., 2010. Global standards, local realities: private agrifood governance and the restructuring of the Kenyan horticulture industry. Econ. Geogr. 86(2), 197-222.

Santos Silva, J., Tenreyro, S., 2011. Further simulation evidence on the performance of the poisson pseudo-maximum likelihood estimator. Econ. Letters 112(2), 220-222.

Santos Silva, J. M. C., Tenreyro, S., 2006. The log of gravity. Rev. Econ. Statist. 88(4), 641658.

Scoppola, M., Raimondi, V., Olper, A., 2018. The impact of EU trade preferences on the extensive and intensive margins of agricultural and food products. Ag. Econ. 49(2), 251263.

Swinnen, J., 2016. Economics and politics of food standards, trade, and development. Ag. Econ. 47(S1), 7-19.

Tadesse, B., White, R., 2010. Cultural distance as a determinant of bilateral trade flows: do immigrants counter the effect of cultural differences? Appl. Econ. Lett. 17(2), 147-152.

UNCTAD, 2016. BANANA: an INFOCOMM Commodity Profile. Technical report, United Nations Conference on Trade and Development. 
van Bergeijk, P. A., Brakman, S., 2010. The gravity model in international trade: advances and applications. Cambridge University Press.

Yu, M., 2010. Trade, democracy, and the gravity equation. J. Devel. Econ. 91(2), 289-300.

\section{Tables}

Table 1. Brief description of the components of the Worldwide Governance Indicators

1. Voice and Accountability: the extent to which a country's citizens are able to participate in selecting their government, as well as freedom of expression, association, and a free media. 
2. Government Effectiveness: the quality of public services, the civil service and the degree of its independence from political pressures, the quality of policy formulation and implementation, and the credibility of the government's commitment to such policies.

3. Control of Corruption: the extent to which public power is exercised for private gain, including both petty and grand forms of corruption, as well as the state by elites and private interests.

4. Regulatory Quality: the ability of the government to formulate and implement sound policies and regulations that permit and promote private sector development.

5. Political stability: captures perceptions of the likelihood that the government will be destabilised or overthrown by unconstitutional or violent means.

6. Rule of Law: the extent to which agents have confidence in and abide by the rules of society, and in particular the quality of contract enforcement, property rights, the police, and the courts, as well as the likelihood of crime and violence.

Source: Kaufmann et al. (2011)

Table 2. Total number of GlobalGAP certified producers per year ('000)

\begin{tabular}{lllll}
\hline Year & Apples & Bananas & Grapes & Fruits and vegetables \\
\hline 2010 & 3302 & 565 & 898 & 16750 \\
\hline
\end{tabular}




\begin{tabular}{lllll}
\hline 2011 & 2913 & 995 & 1039 & 18270 \\
2012 & 3264 & 1099 & 1032 & 18743 \\
2013 & 3530 & 1521 & 1114 & 20164 \\
2014 & 3699 & 1540 & 1370 & 21623 \\
2015 & 3696 & 1576 & 1577 & 24493 \\
\hline
\end{tabular}

Source: GlobalGAP data

Table 3: The effect of private food safety standard and governance distance on product-level exports

\begin{tabular}{lllll}
\hline \multicolumn{3}{l}{ OLS } & \multicolumn{2}{l}{ PPML } \\
\cline { 2 - 4 }$(1)$ & $(2)$ & $(3)$ & (4)
\end{tabular}




\begin{tabular}{|c|c|c|c|c|}
\hline Dependent variable & $\ln X_{i j k t}$ & $\ln X_{i j k t}$ & $X_{i j k t}$ & $X_{i j k t}$ \\
\hline \multirow[t]{2}{*}{ Log Distance $_{i j}$} & $-1.916^{* * *}$ & $-1.947 * * *$ & $-1.359 * *$ & $-1.409 * *$ \\
\hline & $(0.246)$ & $(0.243)$ & $(0.658)$ & $(0.664)$ \\
\hline \multirow[t]{2}{*}{ Language $_{i j}$} & 0.082 & 0.084 & $0.394 *$ & $0.400 *$ \\
\hline & $(0.265)$ & $(0.266)$ & $(0.234)$ & $(0.236)$ \\
\hline \multirow[t]{2}{*}{ Colony $_{i j}$} & 0.395 & 0.390 & $0.675 * * *$ & $0.674 * * *$ \\
\hline & $(0.270)$ & $(0.270)$ & $(0.196)$ & $(0.196)$ \\
\hline \multirow[t]{2}{*}{ Contiguity $_{i j}$} & $1.066^{* *}$ & $1.077 * *$ & $1.982 *$ & 1.886 \\
\hline & $(0.481)$ & $(0.465)$ & (1.177) & $(1.150)$ \\
\hline \multirow[t]{2}{*}{$\mathrm{RTA}_{i j t}$} & $0.994 * *$ & $1.066^{* *}$ & 0.043 & 0.026 \\
\hline & $(0.412)$ & $(0.418)$ & $(0.229)$ & $(0.230)$ \\
\hline \multirow[t]{2}{*}{$\log \left(1+\right.$ Tariff $\left._{i j k t}\right)$} & -0.102 & -0.111 & -0.167 & -0.173 \\
\hline & $(0.163)$ & $(0.164)$ & $(0.108)$ & $(0.108)$ \\
\hline \multirow[t]{2}{*}{ GovDist $_{i j t-1}$} & $-0.458 * * *$ & $-0.599 * * *$ & $-0.216^{*}$ & $-0.450 * * *$ \\
\hline & $(0.076)$ & $(0.082)$ & $(0.112)$ & $(0.123)$ \\
\hline \multirow[t]{2}{*}{ GovDist $_{i j t-1} \times$ GlobalGAP $_{i k t-1}$} & & $0.303 * * *$ & & $0.265 * *$ \\
\hline & & $(0.080)$ & & $(0.119)$ \\
\hline Observations & 6,272 & 6,272 & 23,192 & 23,192 \\
\hline
\end{tabular}

Notes: Robust country-pair-product clustered standard errors in parentheses. $* * *, * *$, $*$ denote statistical significance at 1\%, 5\% and 10\% respectively. Importer-product-time and exporter-product-time fixed effects included in all regressions. Intercepts included but not reported.

Table 4: The effect of private food safety standard and governance distance on product level exports: income level and product heterogeneities 


\begin{tabular}{|c|c|c|c|c|}
\hline \multirow[b]{4}{*}{ Dependent variable } & \multicolumn{2}{|c|}{ By income level } & \multicolumn{2}{|l|}{ By product } \\
\hline & OLS & PPML & OLS & PPML \\
\hline & (1) & (2) & (3) & (4) \\
\hline & $\ln X_{i j k t}$ & $X_{i j k t}$ & $\ln X_{i j k t}$ & $X_{i j k t}$ \\
\hline \multirow[t]{2}{*}{ GovDist $_{i j t-1}$} & $-0.573 * * *$ & $-0.456 * * *$ & $-0.605 * * *$ & $-0.425 * * *$ \\
\hline & $(0.083)$ & $(0.125)$ & $(0.081)$ & $(0.115)$ \\
\hline \multirow[t]{2}{*}{ GovDist $_{i j t-1} \times$ GlobalGAP $_{i k t-1}$ Developing } & $0.323 * * *$ & $0.265^{* *}$ & & \\
\hline & $(0.081)$ & $(0.119)$ & & \\
\hline \multirow[t]{2}{*}{ GovDist $_{i j t-1} \times$ GlobalGAP $_{i k t-1}$ Developed } & -0.097 & 0.493 & & \\
\hline & $(0.284)$ & $(0.320)$ & & \\
\hline \multirow[t]{2}{*}{ GovDist $_{i j t-1} \times$ GlobalGAP $_{i k t-1}$ Apple } & & & $0.337 * * *$ & $0.362 * *$ \\
\hline & & & $(0.130)$ & $(0.156)$ \\
\hline \multirow[t]{2}{*}{ GovDist $_{i j t-1} \times$ GlobalGAP $_{i k t-1}^{\text {Banana }}$} & & & -0.002 & 0.143 \\
\hline & & & $(0.129)$ & $(0.182)$ \\
\hline \multirow[t]{2}{*}{ GovDist $_{i j t-1} \times$ GlobalGAP $_{i k t-1}{ }_{\text {Grape }}$} & & & $0.502 * * *$ & $0.386^{* * *}$ \\
\hline & & & $(0.122)$ & $(0.127)$ \\
\hline Observations & 6,272 & 23,192 & 6,272 & 23,192 \\
\hline
\end{tabular}

Notes: Robust country-pair-product clustered standard errors in parentheses. $* * *, * *, *$ denote statistical significance at $1 \%, 5 \%$ and $10 \%$ respectively. Importer-product-time and exporter-product-time fixed effects included in all regressions. All standard gravity controls have their expected signs but are omitted from the table for brevity. Intercepts included but not reported.

Table 5: Robustness check: bilateral product-level trade between all countries 


\begin{tabular}{|c|c|c|c|c|}
\hline & (1) & (2) & (3) & (4) \\
\hline Dependent variable & $\ln X_{i j k t}$ & $\ln X_{i j k t}$ & $X_{i j k t}$ & $X_{i j k t}$ \\
\hline \multirow[t]{2}{*}{$\log _{\text {Distance }}$} & $-1.284 * * *$ & $-1.279 * * *$ & $-1.477 * * *$ & $-1.476^{* * *}$ \\
\hline & $(0.058)$ & $(0.057)$ & $(0.112)$ & $(0.112)$ \\
\hline \multirow[t]{2}{*}{ Language $_{i j}$} & $0.466 * * *$ & $0.471 * * *$ & $0.324 * *$ & $0.323 * *$ \\
\hline & $(0.113)$ & $(0.113)$ & $(0.160)$ & $(0.160)$ \\
\hline \multirow[t]{2}{*}{ Colony $_{i j}$} & $0.691 * * *$ & $0.681 * * *$ & $0.681 * * *$ & $0.678 * * *$ \\
\hline & $(0.160)$ & $(0.160)$ & $(0.237)$ & $(0.237)$ \\
\hline \multirow[t]{2}{*}{ Contiguity $_{i j}$} & $0.899 * * *$ & $0.908 * * *$ & -0.099 & -0.099 \\
\hline & $(0.132)$ & $(0.132)$ & $(0.200)$ & $(0.200)$ \\
\hline \multirow[t]{2}{*}{$\mathrm{RTA}_{i j t}$} & $0.546 * * *$ & $0.511 * * *$ & $0.791 * * *$ & $0.787 * * *$ \\
\hline & $(0.098)$ & $(0.099)$ & $(0.160)$ & $(0.161)$ \\
\hline \multirow[t]{2}{*}{$\log \left(1+\right.$ Tariff $\left._{i j k t}\right)$} & $-0.422 * * *$ & $-0.428 * * *$ & $-0.304 * * *$ & $-0.302 * * *$ \\
\hline & $(0.052)$ & $(0.052)$ & $(0.082)$ & $(0.082)$ \\
\hline \multirow[t]{2}{*}{ GovDist $_{i j t-1}$} & $-0.067 * * *$ & $-0.164 * * *$ & $-0.128 * * *$ & $-0.172 * * *$ \\
\hline & $(0.020)$ & $(0.029)$ & $(0.033)$ & $(0.051)$ \\
\hline \multirow[t]{2}{*}{ GovDist $_{i j t-1} \times$ GlobalGAP $_{i k t-1}$} & & $0.152 * * *$ & & 0.050 \\
\hline & & $(0.035)$ & & $(0.061)$ \\
\hline Observations & 24,726 & 24,726 & 163,990 & 163,990 \\
\hline
\end{tabular}

Notes: Robust country-pair-product clustered standard errors in parentheses. ${ }^{* * *},{ }^{* *},{ }^{*}$ denote statistical significance at $1 \%, 5 \%$ and $10 \%$ respectively. Importer-product-time and exporter-product-time fixed effects included in all regressions. Intercepts included but not reported.

Table 6: The effect of private food safety standard and governance distance on exports of all fruits and vegetables 


\begin{tabular}{|c|c|c|}
\hline \multirow[b]{3}{*}{ Dependent variable } & OLS & PPML \\
\hline & (1) & (2) \\
\hline & $\ln X_{i j k t}$ & $X_{i j k t}$ \\
\hline \multirow[t]{2}{*}{ Log Distance $_{i j}$} & $-1.851 * * *$ & $-1.249 * * *$ \\
\hline & $(0.155)$ & $(0.161)$ \\
\hline \multirow[t]{2}{*}{ Language $_{i j}$} & $0.710 * * *$ & -0.044 \\
\hline & $(0.154)$ & $(0.258)$ \\
\hline \multirow[t]{2}{*}{ Colony $_{i j}$} & $0.715^{* * *}$ & $0.782 * * *$ \\
\hline & $(0.176)$ & $(0.207)$ \\
\hline \multirow[t]{2}{*}{ Contiguity $_{i j}$} & $0.952 * * *$ & -0.205 \\
\hline & $(0.294)$ & $(0.495)$ \\
\hline \multirow[t]{2}{*}{$\mathrm{RTA}_{i j t}$} & $0.395 * *$ & 0.117 \\
\hline & $(0.190)$ & $(0.146)$ \\
\hline \multirow[t]{2}{*}{$\log \left(1+\operatorname{Tariff}_{i j k t}\right)$} & 0.099 & 0.105 \\
\hline & $(0.090)$ & $(0.073)$ \\
\hline \multirow[t]{2}{*}{ GovDist $_{i j t-1}$} & $-0.328 * * *$ & $-0.189 * * *$ \\
\hline & $(0.049)$ & $(0.066)$ \\
\hline \multirow[t]{2}{*}{ GovDist $_{i j t-1} \times$ GlobalGAP $_{i k t-1}$} & $0.193 * * *$ & $0.170 * * *$ \\
\hline & $(0.042)$ & $(0.059)$ \\
\hline Observations & 14,021 & 27,540 \\
\hline
\end{tabular}

Notes: The dependent variable is aggregate exports of fruits and vegetables from country $i$ to country $j$ in year $t$. Robust country-pair-product clustered standard errors in parentheses. ***, $* *, *$ denote statistical significance at $1 \%, 5 \%$ and $10 \%$ respectively. Intercepts included but not reported. Importer-time and exporter-time fixed effects included in all regressions.

\section{Figures}

Fig. 1. Average bilateral governance distance: 2010 - 2015 (using Germany as the importer)
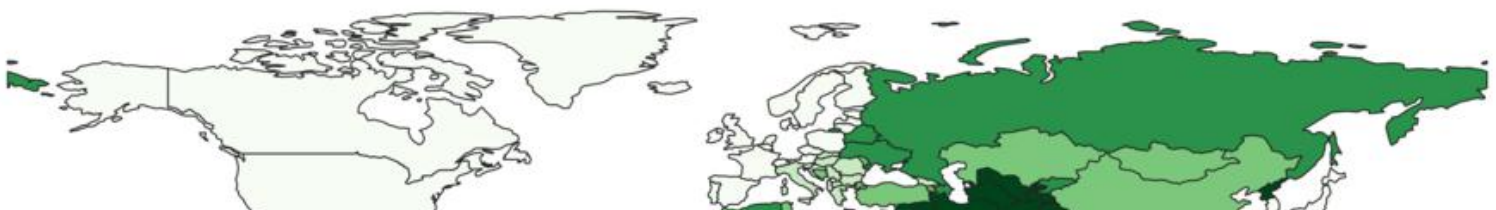
Source: World Bank WGI dataset, authors' own map 